\title{
Minimal assessment of index cases: the point of view of the neurologist
}

\author{
Ernst Hund \\ From First European Congress on Hereditary ATTR amyloidosis \\ Paris, France. 2-3 November 2015
}

The first and most important step is to consider TTRFAP as a diagnosis upon thorough patient history and clinical examination. The further diagnostic process includes the following assessments: clinical examination for polyneuropathic and autonomic signs including temperature and pain sensitivity in the feet. In addition, nerve conduction studies are essential to document large fiber neuropathy. Further on, the patient should be checked for signs of cardiomyopathy and cardiac conduction disorders, since cardiac disease is common in TTR-FAP. Although there will be a characteristic pattern of findings with these examninations, they cannot prove the diagnosis of TTR-FAP. Further investigations include histopathology with demonstration of amyloid by Congo red staining, immunhistochemistry to show that amyloid is composed of TTR, and genetic testing to reveal the specific mutation underlying the disorder.

Published: 2 November 2015

doi:10.1186/1750-1172-10-S1-111

Cite this article as: Hund: Minimal assessment of index cases: the point of view of the neurologist. Orphanet Journal of Rare Diseases 201510 (Suppl 1):111.
University Heidelberg, Germany
Submit your next manuscript to BioMed Central and take full advantage of:

- Convenient online submission

- Thorough peer review

- No space constraints or color figure charges

- Immediate publication on acceptance

- Inclusion in PubMed, CAS, Scopus and Google Scholar

- Research which is freely available for redistribution

Submit your manuscript at www.biomedcentral.com/submit 